Article

\title{
Semi-Minimal Pruned Hedge: A Potential Climate Change Adaptation Strategy in Viticulture
}

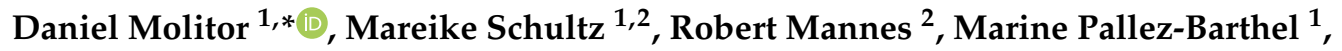 \\ Lucien Hoffmann ${ }^{1}$ and Marco Beyer ${ }^{1}$ \\ 1 Luxembourg Institute of Science and Technology (LIST), Environmental Research and Innovation (ERIN) \\ Department, 41, rue du Brill, L-4422 Belvaux, Luxembourg; mareike.schultz@ivv.etat.lu (M.S.); \\ marine.pallez@list.lu (M.P.-B.); lucien.hoffmann@list.lu (L.H.); marco.beyer@list.lu (M.B.) \\ 2 Institut Viti-vinicole (IVV), Section Viticulture, 8, rue Nic. Kieffer, L-5551 Remich, Luxembourg; \\ robert.mannes@ivv.etat.lu \\ * Correspondence: daniel.molitor@list.lu; Tel.: +352-275-888-5029
}

Received: 18 March 2019; Accepted: 29 March 2019; Published: 2 April 2019

\begin{abstract}
The low-input viticultural training system 'Semi-minimal pruned hedge' (SMPH) is progressively being more widely applied in the Central European grapegrowing regions. The present study examined the influence of (i) the training system (SMPH versus the vertical shoot position (VSP) system), (ii) the timing of shoot topping in SMPH, and (iii) the effects of mechanical thinning in $\mathrm{SMPH}$ on the bunch rot epidemic, grape maturity, and yield. Six-year field trials on Pinot blanc in Luxembourg demonstrated that yield levels in non-thinned SMPH treatments were $74 \%$ higher, and total soluble solids (TSS) at harvest 2.2 brix lower than in VSP. Non-thinned SMPH delayed the bunch rot epidemic and the maturity progress by 18 and 11 days compared to VSP, respectively. Different shoot-topping timings in SMPH did not affect the tested parameters. Mechanical thinning regimes reduced the yield by $28 \%$ (moderate thinning) and 53\% (severe thinning) compared to non-thinned SMPH and increased TSS by 0.8 and 1.3 brix, respectively. Delayed bunch rot epidemic and maturity progress give rise to the opportunity for a longer maturity period in cooler conditions, making this system of particular interest in future, warmer climatic conditions. Providing that yield levels are managed properly, SMPH might represent an interesting climate change adaptation strategy.
\end{abstract}

Keywords: Botrytis cinerea; low-input; mechanical thinning; viticultural training system; yield formation

\section{Introduction}

In many traditional cool climate European grapegrowing regions, the vertical shoot positioning (VSP) system represents the standard viticultural training system [1]. However, winter pruning and canopy management in summer, in particular, are causing high production costs in VSP [2]. Minimal pruning (MP) systems developed in Australia were reported to reduce costs and susceptibility to bunch rot [2]. On the other hand, in European climate conditions, over-cropping, delayed ripening, and alternating yield levels are frequently observed in MP [3]. To overcome these limitations, Intrieri et al. [3] suggested a novel hedge-shaped training system that enables mechanized pruning and mechanized harvesting, the 'semi-minimal pruned hedge' (SMPH). Studies by Intrieri et al. [3] demonstrated reduced management costs, suitability for full mechanization, improved grape yield and quality, as well as a reduced susceptibility to bunch rot in the new system. Based on this, Intrieri et al. [3] recommended SMPH for practical applications. Meanwhile, SMPH is becoming more and more popular in several viticultural regions of Germany [1]. However, the results of multi-annual investigations into the suitability of SMPH in Central European cool climate conditions are limited in 
the scientific literature. Consequently, field trials were established in 2013 in Remich/Luxembourg and investigations continued over a period of six vintages.

Since crop levels in SMPH were reported to be higher than in the traditional VSP system [3,4], cluster thinning might help to avoid over-cropping and, in consequence, inadequate grape maturity. Due to the canopy characteristics of SMPH, cluster thinning is supposed to be practicable more mechanically than manually. Petrie and Clingeleffer [5] demonstrated that mechanical thinning via a modified harvest machine was able to reduce the yield, e.g., in minimally pruned vineyards, in a cost-efficient manner. To the best of our knowledge, no studies about the effect of mechanical thinning in SMPH are available in the scientific literature. For this reason, we address (i) the general suitability of mechanical thinning via a harvest machine in SMPH and (ii) the effect of different thinning strengths on bunch rot epidemic, maturity progress, and yield formation in the present work.

The timing of the first shoot topping in VSP has recently been demonstrated to have an impact on cluster compactness, bunch rot epidemics, and, in consequence, the length of the potential ripening period [6] and will therefore be considered when assessing SMPH in the present study.

Overall, these six-year studies aimed to investigate (i) the general suitability of the SMPH training system under the viticultural conditions in Luxembourg and, more specifically, (ii) the impact of differential shoot topping timings as well as different mechanical thinning regimes on the bunch rot epidemic, grape maturity progress, and yield levels. The traditional cane-pruned VSP acts as a standard (control) system to comparatively assess the results obtained in the different SMPH treatments.

\section{Materials and Methods}

\subsection{Experimental Vineyard and Field Trial Design}

Field trials were carried out in the experimental vineyard of the Institut Viti-Vinicole in Remich, Luxembourg (lat. $49.54^{\circ} \mathrm{N}$; long. $6.35^{\circ}$ E) between 2013 and 2018 on the white Vitis vinifera L. Pinot blanc cultivar. The vineyard in investigation was planted in 2000 and the vines, grafted onto SO4 rootstocks, were trained to a cane-pruned vertical shoot positioning system (VSP) until 2012. The cane height was $0.8 \mathrm{~m}$ from the ground. The training system consisted of two foliage wire pairs and one single foliage wire (horizontal distance between wire stations: $30-35 \mathrm{~cm}$ ). The upper wire pair was installed at a height of $1.8 \mathrm{~m}$ from the ground.

In winter 2012/2013, the vineyard (except the plots of VSP treatment, which continued as VSP over the entire period of investigation) was transferred into the SMPH training system according to Intrieri et al. [3] in the following manner: no winter pruning took place, one additional wire was fixed at a height of approximately $1.8 \mathrm{~m}$, and shoots were clamped between the upper wires with vineyard staples to avoid sliding out in the seasons to come.

The space per plant before and after transfer to SMPH was $2.4 \mathrm{~m}^{2}(2 \mathrm{~m}$ between rows, $1.2 \mathrm{~m}$ between vines).

The field trial was arranged as a randomized block design (four blocks) with four replicates of eight vines per plot. The position of the experimental plots remained unchanged over the entire period of investigation (2013-2018).

The treatments tested (abbreviations in parentheses) were as follows:

- Semi-minimal pruned hedge; first shoot topping approximately one week prior to the beginning of flowering (SMPH ST 1)

- $\quad$ Semi-minimal pruned hedge; first shoot topping at the beginning of flowering (SMPH ST 2)

- Semi-minimal pruned hedge; first shoot topping at the end of flowering (SMPH ST 3)

- Semi-minimal pruned hedge; first shoot topping approximately one week after the end of flowering (SMPH ST 4)

- $\quad$ Cane-pruned vertical shoot positioning $(\mathrm{VSP})=$ standard treatment

- $\quad$ Semi-minimal pruned hedge; moderate mechanical thinning with 320 beats/min (SMPH MT 1)

- $\quad$ Semi-minimal pruned hedge; severe mechanical thinning with 370 beats/min (SMPH MT 2) 
In VSP, winter pruning took place every year; per plant, 12 buds remained and were bound to one horizontal cane. Here, the shoot positioning of primary shoots and lateral shoots was conducted approximately twice during the vegetation period.

No canopy management or winter pruning took place in any of the SMPH treatments. The shoot-topping dates and the developmental stages reached on these dates are given in Table S1. For the VSP, SMPH MT 1, and SMPH MT 2 treatments, shoot topping took place during all seasons on the SMPH ST 4 date.

On the shoot-topping date, shoot tips were (i) topped approximately $5 \mathrm{~cm}$ below the apex or (ii) if the length of a shoot already exceeded the planned final canopy height $(2.0 \mathrm{~m}=$ upper wire $+0.2 \mathrm{~m})$ or width (approximately $0.8 \mathrm{~m}$ ), shoot lengths were limited to these dimensions. Shoots were topped with vineyard shears and this was part of all treatments only once per season; the lateral shoots that appeared were not topped.

Mechanical thinning in the SMPH MT 1 and SMPH MT 2 treatments was conducted every year in the phenophase $\mathrm{BBCH}$ (Biologische Bundesanstalt, Bundessortenamt und CHemische Industrie) 79 [7], representing the time period between the day of reaching $\mathrm{BBCH} 79$ and the day before reaching $\mathrm{BBCH}$ 81. Mechanical thinning dates were 9 August 2013, 23 July 2014, 30 July 2015, 16 August 2016, 20 July 2017, and 23 July 2018. Mechanical thinning was carried out using a grape harvester with a beater amplitude of 320 beats per minute (SMPH MT 1) or 370 beats per minute (SMPH MT 2), respectively. The harvest machine (Grapeliner ${ }^{\circledR}$ 6000, ERO-Gerätebau GMBH, Simmern, Germany) was equipped with six shaker pairs at altitudes of approximately 0.6 to $2.4 \mathrm{~m}$ from the ground (Figure 1).

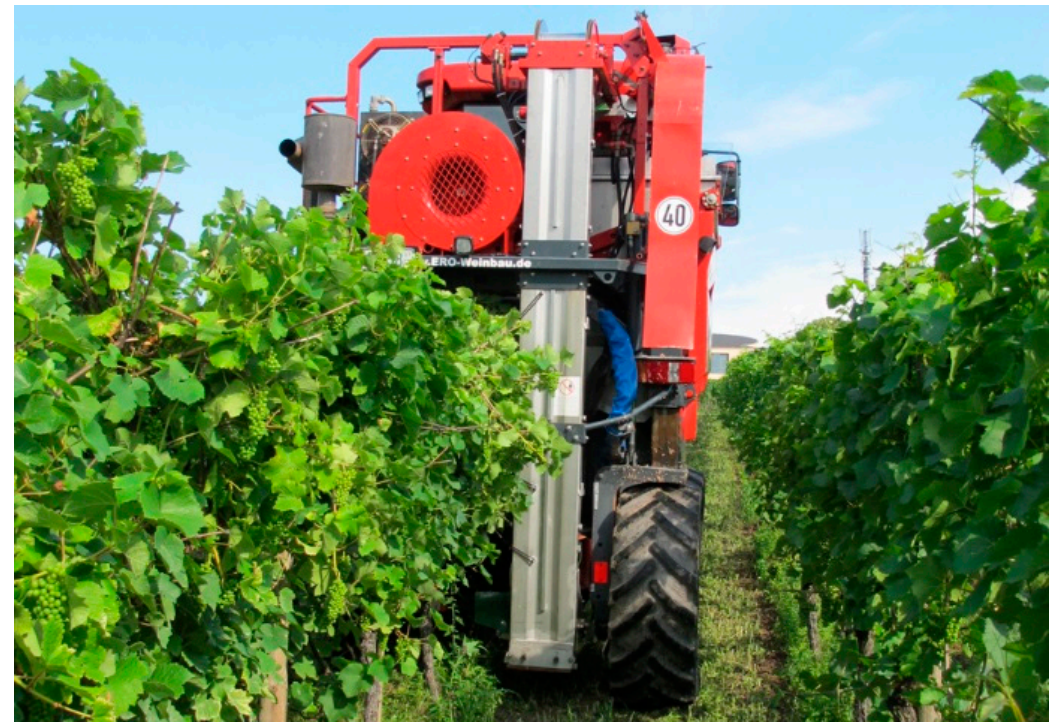

Figure 1. Mechanical thinning in the SMPH MT 1 and SMPH MT 2 treatments on 30 July 2015. SMPH, semi-minimal pruned hedge; MT, mechanical thinning.

Besides experimental treatments, all plots were managed in the same manner throughout the years. Regular background fungicide applications (at 10-12-day intervals) against Plasmopara viticola and Erysiphe necator took place in all seasons. No botryticides were applied.

\subsection{Meteorological Data}

Meteorological data were recorded during the period of examination by a weather station of the national agricultural administration ASTA (Administration des services techniques de l'agriculture) located in Remich/Luxembourg in direct proximity (distance $<50 \mathrm{~m}$ ) of the experimental vineyard. Air temperatures were measured at $2 \mathrm{~m}$ and precipitation at $1 \mathrm{~m}$ from the ground. The weather data can be downloaded from www.agrimeteo.lu. 


\subsection{Assessment of Bud Burst Percentage and Number of Inflorescences per Shoot}

From 2014 to 2018, the bud-burst percentage and number of inflorescences per shoot were assessed on 50 randomly selected buds/shoots per plot. Assessments took place between the plant-growth stages BBCH 17 and 55 on 20 May 2014, 19 May 2015, 31 May 2016, 1 June 2017, and 16 May 2018, respectively.

\subsection{Assessment of the Cluster Morphology}

To investigate the influence of the different treatments on the cluster structure, the cluster density index, according to the protocol by Ipach et al. [8], was assessed as previously described [9]. Fifty clusters per plot were assessed in phenophase BBCH 79 (assessments took place on the date when $\mathrm{BBCH} 81$ was reached in the early ripening cultivar 'Müller-Thurgau' in the same experimental vineyard to guarantee a comparable development in the different years) after the mechanical thinning of the treatments SMPH MT 1 and SMPH MT 2 (20 August 2013, 5 August 2014, 6 August 2015, 18 August 2016, 26 July 2017, 23 July 2018).

\subsection{Assessment of Botrytis cinerea Disease Progress}

The progress of the B. cinerea disease was followed at intervals of 6-14 days between veraison and harvest by examining 50 randomly selected clusters per plot. Disease severity was assessed according to the EPPO (European and Mediterranean Plant Protection Organization) guideline PP1/17 attributing visually observed disease severities to seven classes $(0 \% ; 1-5 \% ; 6-10 \%$; $11-25 \%$; $26-50 \%$; $51-75 \%$; 76-100\%). Average disease severities were calculated by summing the number of observations per class multiplied by the arithmetic mean of the class interval and dividing this sum by the total number of observations $(n=50)$ [10].

To describe the temporal progress of the disease severity, the average values per treatment were plotted against the assessment date (expressed as the day of the year (DOY)). Disease progress curves were fitted to these data according to the sigmoidal Equation (1) as described previously [6]:

$$
y=\frac{100}{1+e^{-\left(\left(x-x_{0}\right) / b\right)}}
$$

where $y$ is the disease severity, $x$ corresponds to the assessment date expressed as the day of the year (DOY), $x_{0}$ is the inflection point of the curve (disease severity of $50 \%$ reached), and $b$ is the slope factor of the curve in the inflection point.

Solving this equation for $x$ provides the time point at which a specific disease severity value was reached. To quantify differences in the temporal position of the annual epidemic of the different treatments, the $\mathrm{x}_{5 \%}$-values (DOY reaching a disease severity of $5 \%$ ) were used following Beresford et al. [11] and Evers et al. [9].

\subsection{Maturation Progress}

The maturation progress was followed at intervals of 6-14 days between veraison and harvest (same dates as for bunch rot assessments) by collecting 30-40 randomly selected berries (clusters from different positions of the canopy; berries of different positions in the cluster) per plot (avoiding berries with visible bunch rot symptoms). Total soluble solids (TSS) were determined from the extracted juice (mixed sample of all berries per plot) using a digital refractometer (RHB-32ATC, Huake Instruments Co. Ltd., Lirenfuzone, Shenzhen, China).

Since berry sugar accumulation after veraison follows a sigmoidal pattern [12,13], sigmoidal maturity progress curves were fitted to observation data according to Equation (2):

$$
y=\frac{a}{1+e^{-\left(\left(x-x_{0}\right) / b\right)}}
$$


where $y$ are the TSS, $x$ corresponds to the sampling date expressed as a day of the year (DOY), $x_{0}$ is the inflection point, $a$ is the maximum of the curve, and $b$ is the slope factor of the curve in the inflection point.

Solving this equation for $\mathrm{x}$ provides the time point at which a specific TSS value was reached. In present investigations, the calculated DOYs reaching 14.17 brix $\left(=60^{\circ}\right.$ Oechsle $)$ were selected for a comparison of the different treatments. Sixty degree Oechsle represents the legal threshold for the production of wines with a protected designation of origin in Luxembourg.

In addition, disease progress curves were plotted against the grape maturation progress (expressed as TSS) according to Equation (1) [13]. In this case, $y$ is the disease severity, $x$ corresponds to the TSS, $x_{0}$ is the inflection point of the curve (disease severity of $50 \%$ reached), and $b$ is the slope factor of the curve in the inflection point.

TSS (brix) calculated at the moment of reaching $5 \%$ disease severity was compared between the different treatments.

\subsection{Yield and Total Soluble Solids at Harvest}

Grapes from each plot were harvested separately (30 October 2013, 29 September 2014, 14 October 2015, 20 October 2016, 27 September 2017, 2 October 2018) and the average yield per plant was calculated. On the harvest date, defined in each year as a compromise between (i) the grape health status as well as (ii) the degree of ripeness in the different treatments, 20 grape clusters were randomly sampled per plot. After pressing, their juice (mixed sample of all clusters) was centrifuged and the TSS were measured by FT-IR (FOSS NIRSystems, Laurel, MD, USA).

\subsection{Data Analyses and Statistics}

Data sets consisting of average values per plot (four replicate plots per treatment) were (after testing Gaussian distribution and homogeneity of variance) analyzed for the effect of the treatment by one-way ANOVAs using SPSS Statistics 19 (IBM, Chicago, IL, USA). For the event that null-hypotheses were rejected $(p \leq 0.05)$, pair-wise comparisons were performed for treatment effects according to Tukey's multiple comparison procedure.

Annual averages of (i) percentages of bud bursts, (ii) number of inflorescences per shoot, (iii) density index, (iv) yield, and (v) TSS at harvest were normalized as a ratio between the average values of the respective treatment and the standard treatment, VSP. Additionally, the annual deviations between VSP and different SMPH treatments were calculated for (i) the $x_{5 \%}$-values (ii) the date reaching 14.12 brix TSS, and (iii) the TSS at the moment of reaching $5 \%$ disease severity. The yield formation of a grapevine is a two-year process [14] and the number of inflorescences per shoot is already determined in the year prior to harvest. Thus, the 2013 results might be influenced by the degree of inflorescence formation in the year before the start of the present trials (2012). Hence, average normalized values as well as average deviations were calculated for the 2014-2018 period ( $n=5$ years) without considering the 2013 results.

\section{Results}

\subsection{Key Meteorological Data}

Key meteorological data are given in Table S2. Average growing season (April-October) temperatures ranged from $14.7^{\circ} \mathrm{C}$ in 2013 to $17.0^{\circ} \mathrm{C}$ in 2018 . The lowest average annual temperatures were measured in $2013\left(9.8^{\circ} \mathrm{C}\right)$ and the highest in 2018 (11.8). The lowest cumulative precipitation within the growing season was observed in $2018(295 \mathrm{~mm})$ and the highest cumulative precipitation in $2013(616 \mathrm{~mm})$. Annual precipitation sums ranged between $540 \mathrm{~mm}$ in 2015 and $813 \mathrm{~mm}$ in 2013 (Table S2). 


\subsection{Percentage of Bud Bursts and Number of Inflorescences Per Cluster}

Average percentages of bud burst ranged from $69.8 \%$ (2014) and $86.9 \%$ (2018). In 2014, the percentage of bud burst in VSP was significantly higher than in SMPH ST 3. In 2017, this was the case for VSP in comparison with SMPH ST 2, SMPH ST 4, SMPH MT 1, and SMPH MT 2. No significant differences were observed in any season between any of the treatments SMPH ST 1 to SMPH ST 4 (Table S3).

The average number of inflorescences per shoot ranged between 0.5 (2014) and 1.1 (2015). In all years of observation, the number of inflorescences per shoot in VSP was significantly higher than in the SMPH treatments. No significant differences were observed in any season between any of the treatments SMPH ST 1 to SMPH ST 4 (Table S4).

\subsection{Cluster Architecture}

Average density indices ranged from 2.7 (2013) to 3.5 (2014). In 2014, the VSP showed significantly higher density index values than all SMPH treatments. No significant differences were observed in any season between any of the treatments SMPH ST 1 to SMPH ST 4. Average normalized density index values ranged from 0.66 in SMPH MT 2 to 1.00 in VSP (Table S5).

\subsection{Bunch Rot and Maturity Progress}

At the final assessment date and over all treatments, on average $B$. cinerea disease severities reached 18.5\% (2013), $11.7 \%$ (2014), $13.7 \%$ (2015), 6.6\% (2016), 20.4\% (2017), and 2.0\% (2018). On the final assessment date, the following significant differences were observed between treatments:

- In 2013, 2015, and 2018, the disease severity for VSP was significantly higher than for each of the SMPH treatments.

- In 2014, the disease severity for VSP was significantly higher than for each of the SMPH treatments with the exception of SMPH ST 2. Besides this, SMPH MT 1 showed significantly lower disease severities than SMPH ST 2.

- In 2017, the disease severity for VSP was significantly higher than for each of the SMPH treatments with the exception of SMPH ST 1. Besides this, SMPH MT 1 and SMPH MT 2 showed significantly lower disease severities than SMPH ST 1.

- In 2016, no significant differences were observed on the final assessment date.

No significant differences were observed on any assessment date between any of the treatments SMPH ST 1 to SMPH ST 4 (Table S6).

Sigmodial curves were fitted to assessment data as a function of time (Figure 2).

Coefficients of determination $\left(R^{2}\right)$ of sigmoidal equations ranged from 0.72 to 1.00 with $p$-values between $<0.0001$ and 0.0681 . Correlations between the assessment data and fitted curves observed were significant in 41 out of 42 'year $x$ treatment-combinations' ( $p \leq 0.05$ ) (Table S7).

Calculated dates reaching a disease severity of $5 \%$ on average for all seven treatments ranged from day of the year 252.1 in 2017 to day of the year 290 in 2013. On average, for the five years from 2014 to 2017, the four non-thinned SMPH treatments reached 5\% disease severity 17.6 days later than the VSP treatments. The highest average deviation between the DOY reaching $5 \%$ disease severity compared to the standard treatment, VSP, was 31.3 days for SMPH MT 1 (Table 1).

The TSS reached for all treatments on the final assessment date was on average 16.0 brix (2013), 20.8 brix (2014), 16.5 brix (2015), 20.9 brix (2016), 19.9 brix (2017), and 20.5 brix (2018). At the final assessment date, the following significant differences were observed between treatments:

- $\quad$ In 2013, TSS values in VSP and SMPH MT 1 and SMPH MT 2 were significantly higher than in non-thinned SMPH treatments.

- In 2015 and 2018, TSS values in VSP and SMPH MT 2 were significantly higher than in non-thinned SMPH treatments. 
In 2016, TSS in VSP as well as in both thinned SMPH treatments were significantly lower than in SMPH ST 1 and SMPH ST 2.

- $\quad$ In 2014 and 2017, no significant differences were observed on the final assessment date.

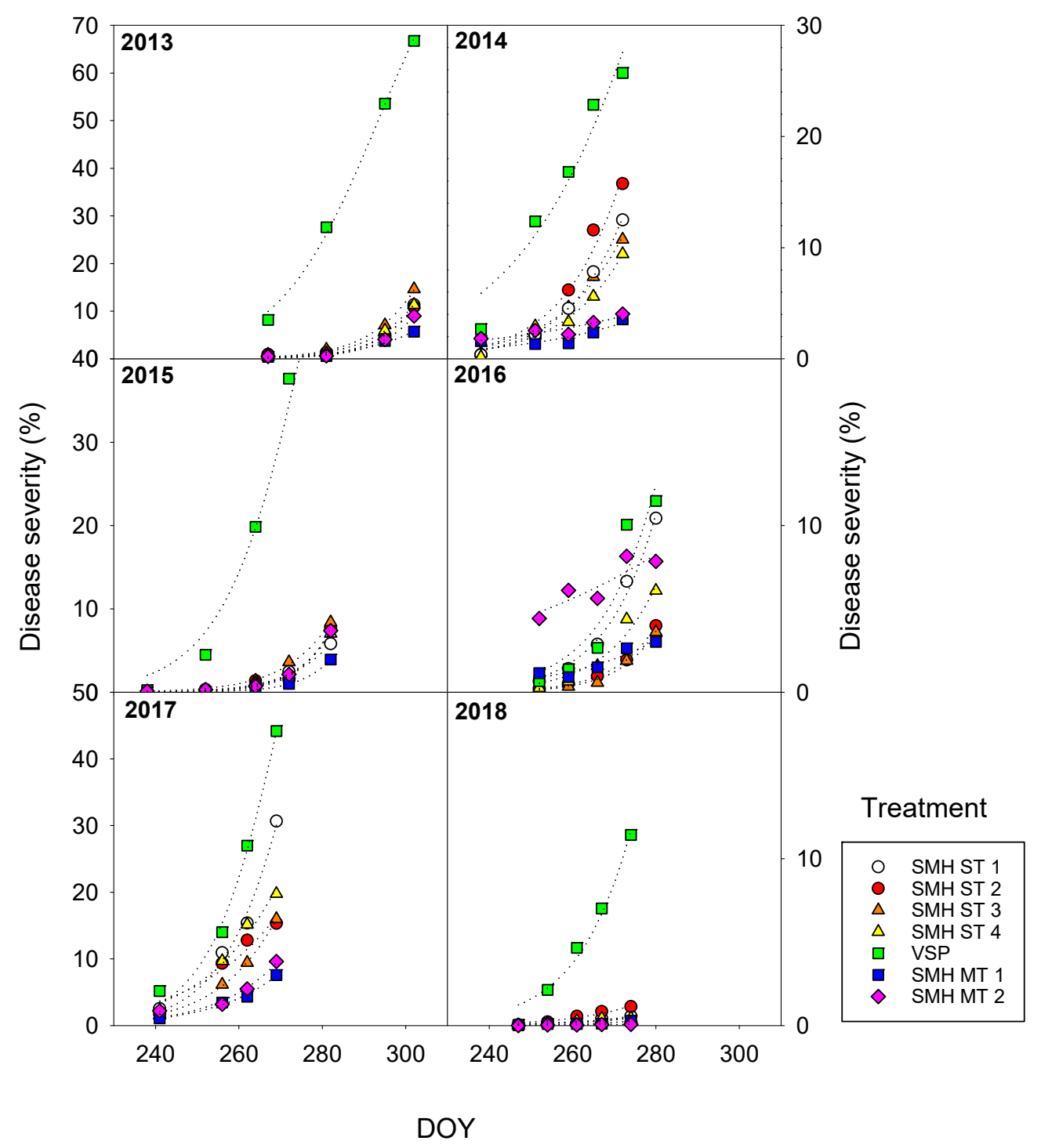

Figure 2. Progress of the disease severity of Botrytis cinerea in the different treatments between 2013 and 2018 as functions of the assessment date (day of the year (DOY)). Plot symbols represent the observed disease severities, with lines showing the calculated progress according to the sigmoidal equation type $y=100 /\left(1+e^{-\left(\left(x-x_{0}\right) / b\right)}\right)$. SMPH, semi-minimal pruned hedge; ST, shoot topping; VSP, vertical shoot positioning; MT, mechanical thinning.

TSS in non-thinned SMPH treatments did not differ significantly on the final assessment date with the exception of SMPH ST 1 in 2016, which reached significantly higher TSS values than SMPH ST 3 and SMPH ST 4 (Table S8).

When fitting sigmoidal equations to data illustrating maturity progress (Figure 3), coefficients of determination $\left(R^{2}\right)$ ranged from 0.96 to 1.00 with $p$-values between 0.0003 and 0.2092 . 
Table 1. Calculated dates (day of the year (DOY)) for reaching 5\% bunch rot disease severity between 2013 and 2018 as well as deviations ( $\Delta$ ) between the DOY for reaching 5\% disease severity in one treatment in a specific year and the DOY for reaching 5\% disease severity in the standard treatment, VSP, in that year. Average (2014-2017) deviations of different treatments are depicted. Since in 2018 5\% disease severity were not reached in all treatments, calculated data were not shown.

\begin{tabular}{|c|c|c|c|c|c|c|c|c|c|c|c|c|c|}
\hline Treatment * & 2013 & $\Delta$ & 2014 & $\Delta$ & 2015 & $\Delta$ & 2016 & $\Delta$ & 2017 & $\Delta$ & 2018 & $\Delta$ & $\begin{array}{c}\text { Average } \\
(2014-2017) \Delta\end{array}$ \\
\hline SMPH ST 1 & 295.2 & 37.0 & 260.2 & 25.6 & 280.4 & 32.6 & 271.1 & 2.5 & 249.3 & 4.3 & & & 16.3 \\
\hline SMPH ST 2 & 295.0 & 36.9 & 256.4 & 21.8 & 278.8 & 31.0 & 282.3 & 13.8 & 246.7 & 1.7 & & & 17.1 \\
\hline SMPH ST 3 & 291.2 & 33.0 & 260.3 & 25.7 & 276.3 & 28.5 & 282.9 & 14.4 & 253.8 & 8.9 & & & 19.4 \\
\hline SMPH ST 4 & 293.4 & 35.3 & 263.2 & 28.6 & 279.0 & 31.2 & 277.1 & 8.5 & 246.7 & 1.7 & & & 17.5 \\
\hline VSP & 258.1 & 0.0 & 234.6 & 0.0 & 247.8 & 0.0 & 268.5 & 0.0 & 244.9 & 0.0 & & & \\
\hline SMPH MT 1 & 300.0 & 41.9 & 283.8 & 49.2 & 283.8 & 36.1 & 290.5 & 22.0 & 262.9 & 18.0 & & & 31.3 \\
\hline SMPH MT 2 & 296.8 & 38.7 & 282.7 & 48.1 & 278.8 & 31.0 & 253.9 & -14.7 & 260.1 & 15.2 & & & 19.9 \\
\hline Average & 290.0 & 31.8 & 263.0 & 28.1 & 275.0 & 27.2 & 275.2 & 6.6 & 252.1 & 7.1 & & & 17.3 \\
\hline
\end{tabular}

* SMPH, semi-minimal pruned hedge; ST, shoot topping; VSP, vertical shoot positioning; MT, mechanical thinning. 


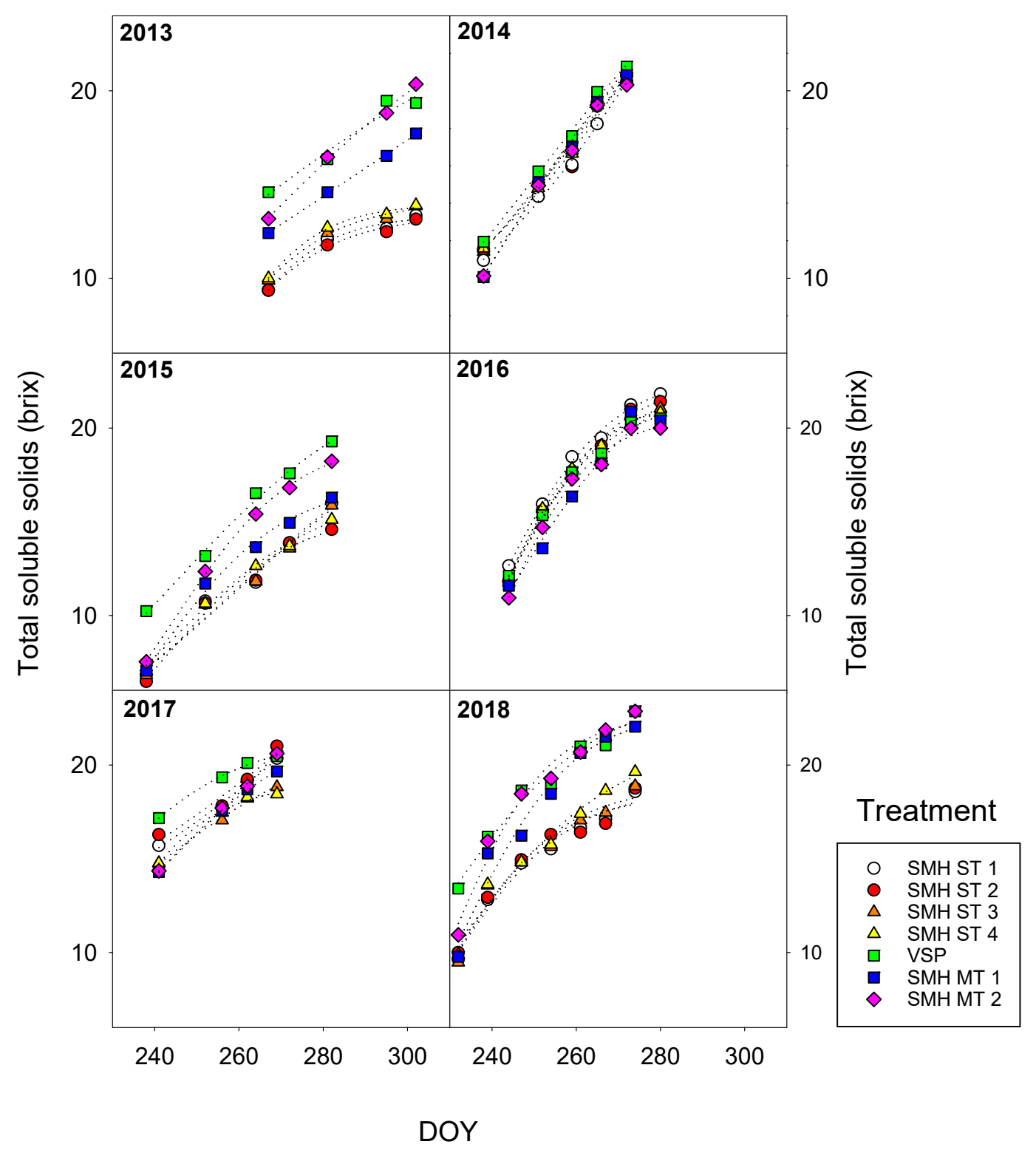

Figure 3. Progress of the total soluble solids in the different treatments between 2013 and 2018 as functions of the assessment date (DOY). Plot symbols represent the observed disease severities, with lines showing the calculated progress according to the sigmoidal equation type $y=a /(1+$ $\left.e^{-\left(\left(x-x_{0}\right) / b\right)}\right)$. SMPH, semi-minimal pruned hedge; ST, shoot topping; VSP, vertical shoot positioning; MT, mechanical thinning.

Correlations between recorded data and fitted curves were significant in 33 of 42 'year $x$ treatment-combinations' ( $p \leq 0.05$ ). Non-significant correlations were limited to 2013 and 2017, for which only four assessment data sets were available (Table S9).

Calculated dates (DOY), reaching on average 14.12 brix for all seven treatments, ranged from 223.6 in 2017 to 267.8 in 2015. In 2013, 14.12 brix was not reached in the non-thinned treatments of SMPH.

In the five years from 2014 to 2018, the level of 14.12 brix was reached on average 11 days later in the four non-thinned SMPH treatments than with VSP. The highest average deviation observed between the DOY reaching 14.12 brix in an SMPH treatment and the standard VSP treatment was 12.5 days in SMPH ST 4 (Table 2). 
Table 2. Calculated dates (day of the year (DOY)) for reaching 14.12 brix between 2013 and 2018 as well as deviations $(\Delta)$ between the DOY for reaching 14.12 brix in one treatment in a specific year and the DOY for reaching 14.12 in the standard treatment, VSP, in that year. Average (2014-2018) deviations of different treatments are depicted.

\begin{tabular}{|c|c|c|c|c|c|c|c|c|c|c|c|c|c|}
\hline Treatment & 2013 & $\Delta$ & 2014 & $\Delta$ & 2015 & $\Delta$ & 2016 & $\Delta$ & 2017 & $\Delta$ & 2018 & $\Delta$ & $\begin{array}{c}\text { Average } \\
(2014-2018) \Delta\end{array}$ \\
\hline SMPH ST 1 & $\mathrm{NR} *$ & & 251.0 & 5.3 & 272.9 & 18.2 & 246.7 & -1.8 & 230.5 & 2.8 & 242.3 & 29.3 & 10.7 \\
\hline SMPH ST 2 & NR & & 249.1 & 3.3 & 276.8 & 22.1 & 247.6 & -0.9 & 227.6 & -0.2 & 238.8 & 25.9 & 10.0 \\
\hline SMPH ST 3 & NR & & 247.8 & 2.1 & 273.5 & 18.8 & 247.5 & -1.0 & 237.5 & 9.8 & 241.7 & 28.8 & 11.7 \\
\hline SMPH ST 4 & NR & & 248.2 & 2.5 & 273.7 & 19.0 & 247.6 & -0.9 & 238.8 & 11.0 & 243.9 & 31.0 & 12.5 \\
\hline VSP & 265.0 & 0.0 & 245.8 & 0.0 & 254.7 & 0.0 & 248.5 & 0.0 & 227.8 & 0.0 & 213.0 & 0.0 & 0.0 \\
\hline SMPH MT 1 & 278.4 & 13.3 & 249.1 & 3.3 & 264.9 & 10.2 & 253.4 & 4.9 & 240.3 & 12.5 & 242.5 & 29.5 & 12.1 \\
\hline SMPH MT 2 & 271.0 & 5.9 & 249.2 & 3.5 & 258.5 & 3.8 & 250.3 & 1.8 & 239.8 & 12.0 & 218.2 & 5.3 & 5.3 \\
\hline Average & & & 248.6 & 2.8 & 267.8 & 13.1 & 248.8 & 0.3 & 234.6 & 6.8 & 243.3 & 21.4 & 8.9 \\
\hline
\end{tabular}

$*$ NR $=14.12$ brix not reached 
Sigmoidal equations of the type $y=100 /\left(1+e^{-\left(\left(x-x_{0}\right) / b\right)}\right)$, which describe the disease progress as a function of maturation progress (TSS in brix) (Figure 4), reached coefficients of determination between 0.66 and 1.00 with $p$-values between $<0.0001$ and 0.0949 .

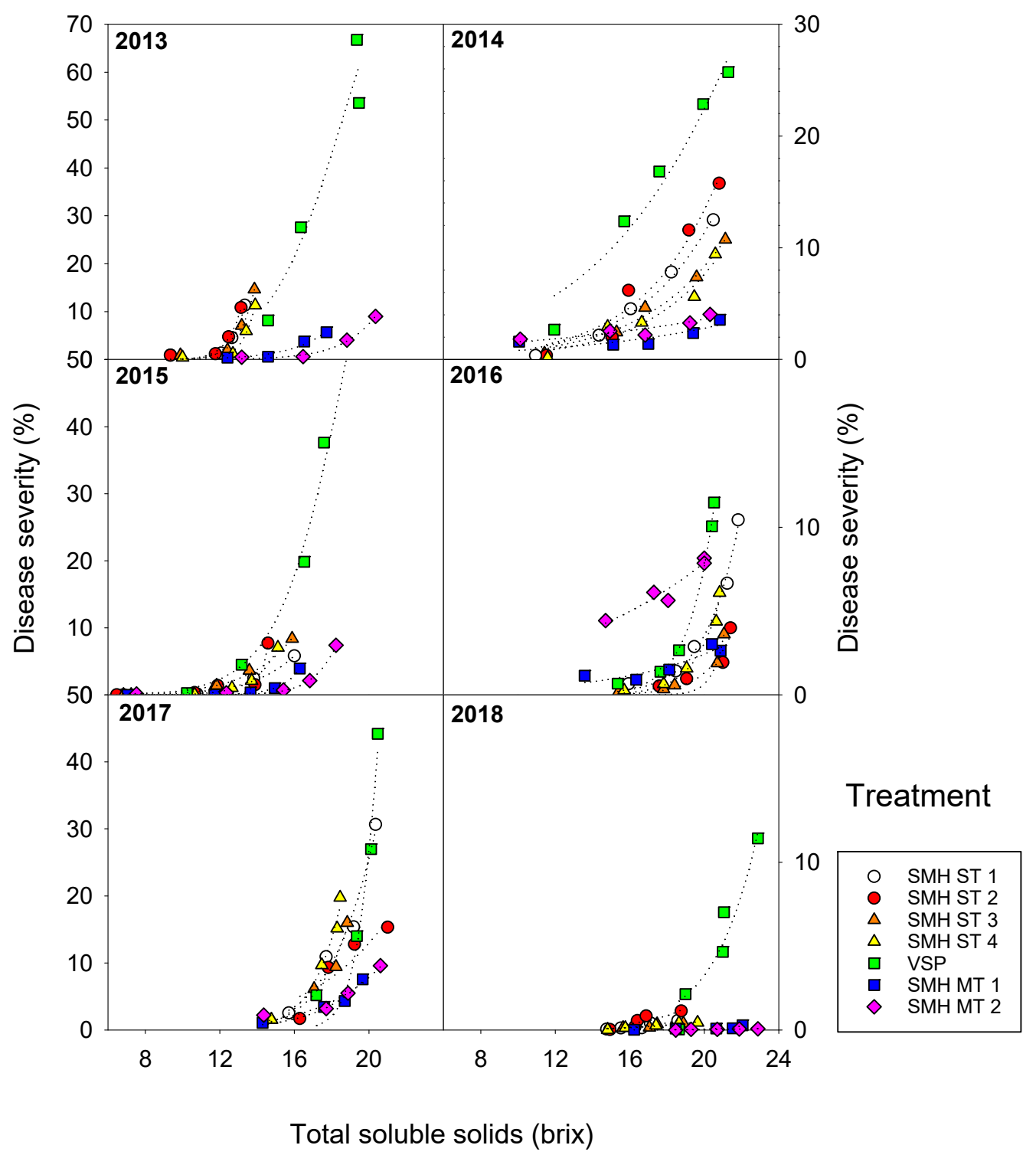

Figure 4. Progress of the disease severity of B. cinerea in the different treatments between 2013 and 2018 as functions of the total soluble solids. Plot symbols represent the observed disease severities, with the lines showing the calculated progress according to the sigmoidal equation type $y=100 /(1+$ $\left.e^{-\left(\left(x-x_{0}\right) / b\right)}\right)$. SMPH, semi-minimal pruned hedge; ST, shoot topping; VSP, vertical shoot positioning; MT, mechanical thinning.

In 38 of 42 'year $x$ treatment-combinations', disease progress was significantly correlated with the maturation progress (Table S10).

TSS calculated at the moment disease severity reached 5\% ranged between 14.4 brix in 2013 and 20.5 brix in 2016 (average of all seven treatments). Over the year 2014 to 2017, 5\% disease severity was reached on average at higher TSS levels in all SMPH treatments than in VSP treatments. From 2014 to 2017, the four non-thinned SMPH treatments reached on average 5\% disease severity, with TSS levels being 1.8 brix higher than for VSP (Table 3). 
Table 3. Calculated total soluble solids (brix) on the day of the year (DOY) for reaching $5 \%$ disease severity between 2013 and 2018 as well as deviations ( $\Delta$ ) between the total soluble on the day of the year for reaching $5 \%$ disease severity in a specific year and the total soluble on the days of the year for reaching $5 \%$ disease severity in the standard treatment, VSP, in that year. Average (2014-2017) deviations of different treatments are depicted. Since in $20185 \%$ disease severity were not reached in all treatments, calculated data were not shown.

\begin{tabular}{|c|c|c|c|c|c|c|c|c|c|c|c|c|c|}
\hline Treatment & 2013 & $\Delta$ & 2014 & $\Delta$ & 2015 & $\Delta$ & 2016 & $\Delta$ & 2017 & $\Delta$ & 2018 & $\Delta$ & $\begin{array}{c}\text { Average } \\
(2014-2017) \Delta\end{array}$ \\
\hline SMPH ST 1 & 12.8 & 0.0 & 16.8 & 5.6 & 15.6 & 2.2 & 20.6 & 1.2 & 16.7 & -2.0 & & & 1.8 \\
\hline SMPH ST 2 & 12.6 & -0.2 & 16.2 & 5.0 & 14.4 & 1.0 & 21.9 & 2.5 & 16.3 & -2.4 & & & 1.5 \\
\hline SMPH ST 3 & 12.9 & 0.2 & 17.8 & 6.6 & 14.6 & 1.2 & 21.3 & 1.9 & 16.9 & -1.7 & & & 2.0 \\
\hline SMPH ST 4 & 13.4 & 0.6 & 18.4 & 7.2 & 14.7 & 1.3 & 20.7 & 1.2 & 16.6 & -2.0 & & & 1.9 \\
\hline VSP & 12.7 & 0.0 & 11.2 & 0.0 & 13.4 & 0.0 & 19.4 & 0.0 & 18.6 & 0.0 & & & 0.0 \\
\hline SMPH MT 1 & 17.4 & 4.7 & 24.8 & 13.6 & 16.5 & 3.1 & 23.9 & 4.5 & 18.7 & 0.1 & & & 5.3 \\
\hline SMPH MT 2 & 19.3 & 6.6 & 23.9 & 12.7 & 17.8 & 4.4 & 16.0 & -3.4 & 18.6 & -0.1 & & & 3.4 \\
\hline Average & 14.4 & 1.7 & 18.5 & 7.2 & 15.3 & 1.9 & 20.5 & 1.1 & 17.5 & -1.1 & & & 2.3 \\
\hline
\end{tabular}


Temporal day of the year (DOY) deviations, reaching 5\% disease severity in the different treatments, were plotted against the temporal day of the year (DOY) deviations that reached 14.12 brix in the different treatments (Figure 5).

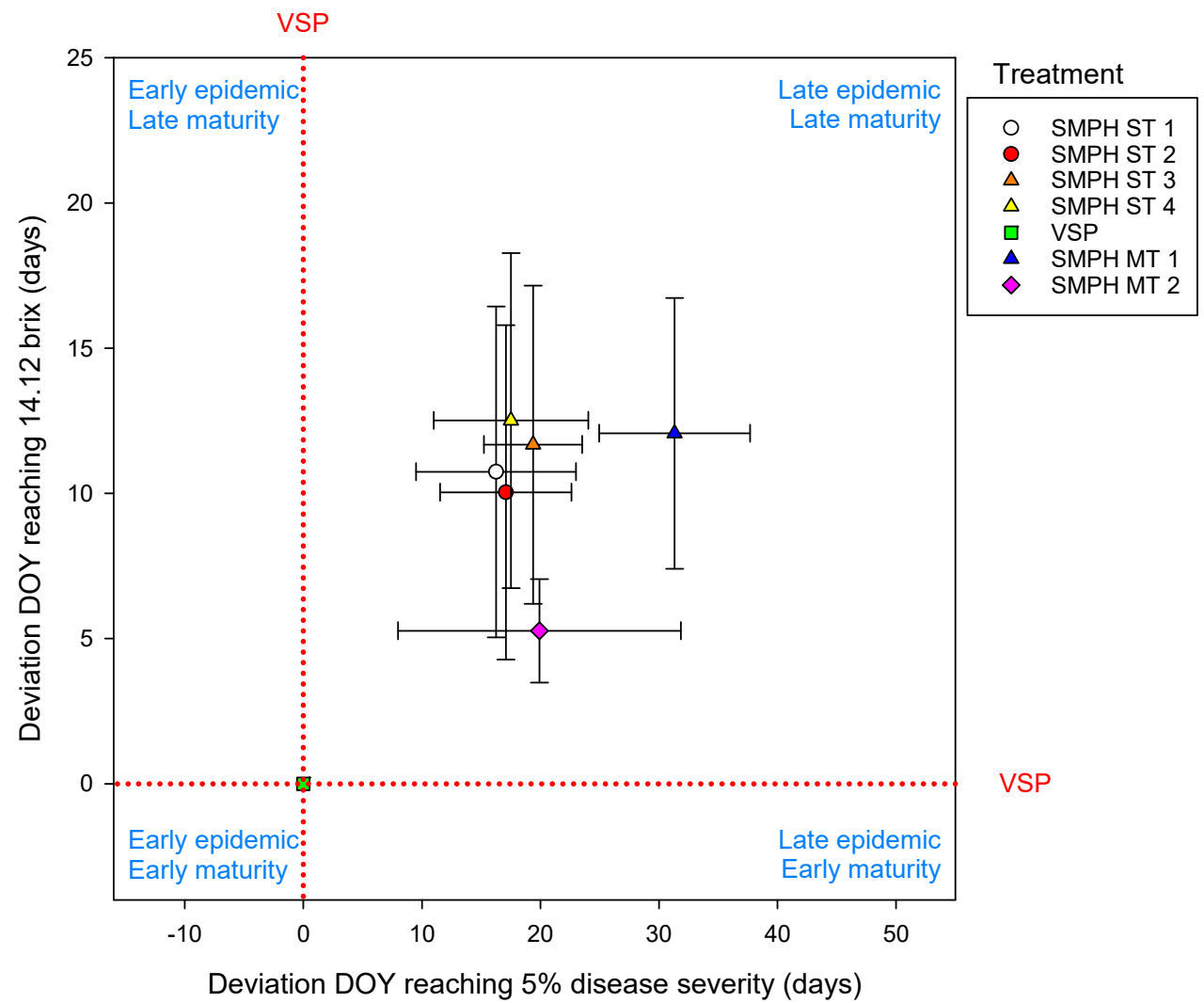

Figure 5. Temporal deviations of the day of the year (DOY) for reaching 5\% disease severity in the different treatments compared to the standard treatment, VSP, plotted against the temporal deviations of the day of the year (DOY) for reaching 14.12 brix in the different treatments compared to VSP. Data from 2014 to 2017. Error bars = standard errors.

\subsection{Yield and TSS at Harvest}

The average yield across all treatments was $6.5 \mathrm{~kg} / \mathrm{plant}$ (2013), $3.7 \mathrm{~kg} / \mathrm{plant}$ (2014), $9.5 \mathrm{~kg} / \mathrm{plant}$ (2015), $1.4 \mathrm{~kg} /$ plant (2016), 4.2 (2017) kg/plant, and $5.5 \mathrm{~kg} /$ plant (2018).

Significant differences between the yield levels were observed in the following cases:

- In 2013 and 2015, the yield in VSP and SMPH MT 2 was significantly lower than in the non-thinned SMPH treatments.

- $\quad$ In 2016, the yield in VSP was significantly higher than in SMPH ST 1 and SMPH ST 2.

- In 2018, the yield in SMPH MT 1 and SMPH MT 2 was significantly lower than in the non-thinned SMPH treatments.

- $\quad$ In 2014 and 2017, no significant differences were observed.

No significant differences were observed in any year between the different non-thinned treatments of SMPH ST 1.

Average normalized yields were lowest in SMPH MT 2 (0.81) and highest in SMPH 4 (1.81). Compared to the average of the non-thinned SMPH treatments, from 2014 to 2018, the yield reduction in SMPH MT 1 and SMPH MT 2 reached on average 28 and 53\%, respectively (Table 4). 
Table 4. Average values of the yield (kg/plant) between 2013 and 2018 as well as average normalized yield values for 2014-2018 (value of the yield of the respective treatment in a specific year/value of the standard treatment, VSP, in that year). Yield values of different treatments in the same year marked with the same letter did not differ significantly (according to Tukey's multiple comparison procedure $(p \leq 0.05))$. Average (2014-2018) normalized yield values are depicted. If no letter codes are indicated, differences were non-significant.

\begin{tabular}{cccccccc}
\hline Treatment & $\mathbf{2 0 1 3}$ & $\mathbf{2 0 1 4}$ & $\mathbf{2 0 1 5}$ & $\mathbf{2 0 1 6}$ & $\mathbf{2 0 1 7}$ & $\mathbf{2 0 1 8}$ & $\begin{array}{c}\text { Average } \\
\text { Normalized Yield } \\
\text { (2014-2018) }\end{array}$ \\
\hline SMPH ST 1 & $9.5 \mathrm{c}$ & 3.8 & $12.5 \mathrm{~b}$ & $0.9 \mathrm{a}$ & 5.3 & $7.6 \mathrm{bc}$ & 1.8 \\
SMPH ST 2 & $8.8 \mathrm{bc}$ & 3.8 & $11.6 \mathrm{~b}$ & $0.9 \mathrm{a}$ & 4.5 & $8.0 \mathrm{c}$ & 1.7 \\
SMPH ST 3 & $9.2 \mathrm{c}$ & 4.6 & $11.4 \mathrm{~b}$ & $1.4 \mathrm{ab}$ & 4.9 & $7.5 \mathrm{bc}$ & 1.7 \\
SMPH ST 4 & $7.6 \mathrm{bc}$ & 4.4 & $11.3 \mathrm{~b}$ & $1.6 \mathrm{ab}$ & 5.5 & $7.8 \mathrm{bc}$ & 1.8 \\
VSP & $3.3 \mathrm{a}$ & 3.7 & $4.8 \mathrm{a}$ & $2.7 \mathrm{~b}$ & 1.9 & $3.7 \mathrm{ab}$ & 1.0 \\
SMPH MT 1 & $4.8 \mathrm{ab}$ & 3.2 & $8.4 \mathrm{ab}$ & $1.2 \mathrm{ab}$ & 4.7 & $2.8 \mathrm{a}$ & 1.3 \\
SMPH MT 2 & $2.1 \mathrm{a}$ & 2.6 & $6.4 \mathrm{a}$ & $1.0 \mathrm{a}$ & 2.5 & $1.2 \mathrm{a}$ & 0.8 \\
\hline Average & 6.5 & 3.7 & 9.5 & 1.4 & 4.2 & 5.5 & 1.4 \\
\hline
\end{tabular}

For all treatments, the TSS at harvest date were on average 15.5 (2013), 20.8 (2014), 15.4 (2015), 21.2 (2016), 19.9 (2017), and 21.0 brix (2018). The average normalized TSS at harvest were lowest in SMPH ST 4 (0.90) and highest in VSP (1). Compared to the average of the non-thinned SMPH treatments, from 2014 to 2018, the increase of TSS at harvest in SMPH MT 1 and SMPH MT 2 reached 0.8 and 1.3 brix on average, respectively (Table 5 ).

Table 5. Average values of the total soluble solids (TSS) at harvest (brix) between 2013 and 2018 as well as average normalized TSS at harvest values for 2014-2018 (value of the TSS at harvest of the respective treatment in a specific year/value of the standard treatment, VSP, in that year). TSS at harvest values of different treatments in the same year marked with the same letter did not differ significantly (according to Tukey's multiple comparison procedure $(p \leq 0.05))$. Average (2014-2018) normalized TSS at harvest values are depicted. If no letter codes are indicated, differences were non-significant.

\begin{tabular}{cccccccc}
\hline Treatment & $\mathbf{2 0 1 3}$ & $\mathbf{2 0 1 4}$ & $\mathbf{2 0 1 5}$ & $\mathbf{2 0 1 6}$ & $\mathbf{2 0 1 7}$ & $\mathbf{2 0 1 8}$ & $\begin{array}{c}\text { Average } \\
\text { Normalized TSS at } \\
\text { Harvest (2014-2018) }\end{array}$ \\
\hline SMPH ST 1 & $12.9 \mathrm{a}$ & 21.1 & $13.3 \mathrm{a}$ & $22.3 \mathrm{~b}$ & 20.4 & 19.7 & 0.9 \\
SMPH ST 2 & $12.7 \mathrm{a}$ & 20.8 & $15.0 \mathrm{ab}$ & $21.8 \mathrm{ab}$ & 21.0 & 19.7 & 0.9 \\
SMPH ST 3 & $13.4 \mathrm{a}$ & 20.5 & $13.6 \mathrm{a}$ & $21.5 \mathrm{ab}$ & 18.8 & 19.2 & 0.9 \\
SMPH ST 4 & $13.4 \mathrm{a}$ & 20.6 & $13.7 \mathrm{a}$ & $21.3 \mathrm{ab}$ & 18.5 & 19.4 & 0.9 \\
VSP & $18.9 \mathrm{c}$ & 21.3 & $19.0 \mathrm{c}$ & $20.3 \mathrm{a}$ & 20.5 & 23.2 & 1.0 \\
SMPH MT 1 & $17.3 \mathrm{~b}$ & 20.8 & $15.1 \mathrm{ab}$ & $21.0 \mathrm{ab}$ & 19.7 & 22.9 & 1.0 \\
SMPH MT 2 & $19.9 \mathrm{c}$ & 20.3 & $17.8 \mathrm{bc}$ & $20.4 \mathrm{a}$ & 20.6 & 23.2 & 1.0 \\
\hline Average & 15.5 & 20.8 & 15.4 & 21.2 & 19.9 & 21.0 & 0.9 \\
\hline
\end{tabular}

For the different treatments, average (2014-2018) normalized yields were plotted against average normalized TSS at harvest. On average, for 2014 to 2018, non-thinned treatments of SMPH as well as SMPH MT 1 obtained higher yields, as well as lower TSS than VSP, whereas SMPH MT 2 obtained lower yields and lower TSS (Figure 6). 


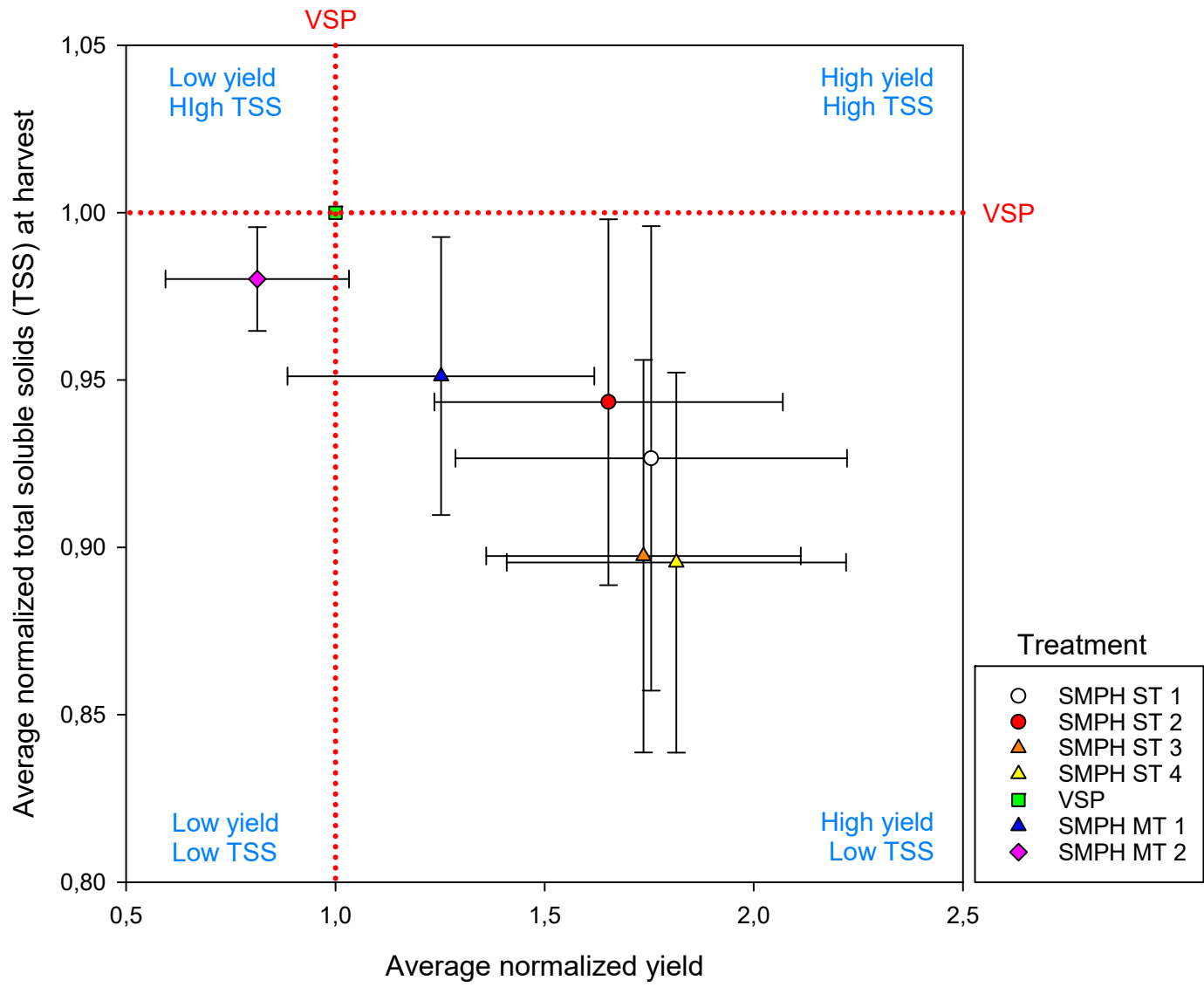

Figure 6. Average normalized yield (ratio of the yield in the different treatments and the yield in the standard treatment, VSP) plotted against the average normalized TSS (ratio of the TSS in the different treatments and the TSS in VSP) at harvest. Data from 2014 to 2018. Error bars = standard errors.

\section{Discussion}

\subsection{General Behaviour of Non-Thinned SMPH}

The number of buds per plant in SMPH was shown to be several times higher than in the traditional VSP system [3]. To avoid excessive over-cropping in SMPH, different steps of self-regulation are necessary. The present results indicate a decrease in the percentage of bud burst as well as a significantly reduced number of inflorescences per shoot in SMPH treatments compared to VSP, confirming the observations of Intrieri et al. [3].

However, the number of clusters per plant in SMPH remained much higher than in VSP [3]. As a further step in self-regulation, the size (and consequently the weight) of clusters has been observed to be smaller in SMPH than in VSP as a result of (i) the reduced size of the berries, as well as (ii) a reduced number of berries [1,4]. Furthermore, the structure of clusters in SMPH has been observed in the studies of Intrieri et al. [3] and Kraus et al. [1] to be less compact than in VSP. Present data indicate a reduced compactness of SMPH clusters even though the differences were not significant. Generally, a strong link between cluster compactness and bunch rot susceptibility was observed in several studies in different cultivars and different viticultural regions $[6,15,16]$. The underlying physiological and epidemiological reasons for this relationship have been discussed in detail in a previous work [17]. Consequently, on the final assessment dates, the disease severities of B. cinerea in SMPH were lower than in the standard treatment, VSP, in all years of the investigation, confirming the observations of Intrieri et al. [3]. Both bunch rot epidemics and TSS (as an indicator for grape maturity) progress follow a sigmoidal pattern over time $[12,17]$ and, hence, can be adequately simulated by sigmoidal equations allowing for the calculation of precise dates when specific disease severity or maturity levels are 
reached. Non-thinned SMPH treatments delayed the day of the year for reaching $5 \%$ disease severity (average for 2014-2017) by 18 days on average. In the environmental conditions of the Luxembourgish Moselle region, as well as of many other cool-climate winegrowing regions, the timing of the harvest is more often determined by crop health status than by optimum grape maturity [18]. The delay of the bunch rot epidemic observed in SMPH, in fact, enabled an average temporal benefit of approximately three weeks before the grapes reached a disease severity threshold that forced the grower to harvest them before bunch rot jeopardized yield and/or wine quality.

The average yield in non-thinned SMPH treatments was considerably higher than in VSP. This was the result of the much higher number of buds per plant [3,4]. Despite the observed and aforementioned mechanisms of self-regulation, from 2014 to 2018, the average yield in non-thinned SMPH treatments was $78 \%$ higher than in the standard system. Consequently, the legal thresholds of marketable grapes/wine per ha in Luxemburg were partially exceeded. In non-thinned SMPH, the yield fluctuated greatly from year to year. Coefficients of variation (cv; standard deviation/mean) in the non-thinned SMPH treatments reached 66\% between 2014 and 2018, which is twice as high as in VSP (33\%). This indicates a tendency towards alternate bearing in SMPH as described by Intrieri et al. [3]. However, we observed a tendency towards more moderate yield levels (although still fluctuating) with ongoing temporal distance to the year of transfer from VSP to SMPH.

The bunch rot epidemic has to be considered in strong relationship with the maturity progress, especially in the case of marked differences in the yield levels [6]. In fact, as a consequence of the (on average) higher crop load, non-thinned SMPH treatments also delayed the maturity progress-on average by 11 days - until the legal threshold for wines marketable as wines of protected designation of origin had passed. This confirms observations by Walg et al. [4], who generally observed a maturity delay of 1-2 weeks in SMPH compared to VSP. Besides a frequently higher crop load, the canopy morphology has also been identified as a reason for this maturity delay. In fact, berry development in SMPH is more inhomogeneous than in VSP [4]. This is the case due to the lower sun and light exposure of shadowed clusters and, in consequence, lower temperatures inside the complex canopy [1]. Generally, in the present investigation, the delay of the maturity progress was observed to be lower than the delay of the bunch rot epidemic. For example, when considering a specific disease level (in our case defined as 5\% following the definition of Beresford et al. [11]) as a determining factor for the harvest, non-thinned SMPH treatments would have reached, on average for 2014-2018, 1.8 more TSS at harvest than the standard system, VSP. However, generally, it must be kept in mind that (i) the length of the vegetation period is limited and (ii) the maturity progress ceases at a certain time of year. Consequently, even if the grape health status allowed for a further potential delay in the harvest date, grapes in SMPH might not ever reach full maturity in phenologically late vintages and/or in the event of high/excessive crop load (as observed in 2013 where the legal minimum TSS levels for wines of protected designation of origin were not reached by any of the non-thinned SMPH treatments). However, (i) the more moderate yield levels with ongoing temporal distance to the transfer from VSP to SMPH and (ii) the potential temporal buffer for a continuation of the maturation period after the harvest period of the traditional VSP due to climate change (earlier start of the maturation period [19]; temporal prolongation of the potential vegetation period in autumn [20]), are supposed to compensate for the delayed maturation.

\subsection{Timing of Shoot Topping}

While investigations by Molitor et al. [6] demonstrated the importance of the timing of the first shoot topping in VSP on the bunch rot epidemic as well as on grape maturity and yield, in the present investigations, the moment that the shoot topping was carried out showed no significant effects. This absence of significant differences may be explained by the fact that the temporal distance between the earliest and the latest moment of shoot topping was relatively low, approximately three weeks. In fact, in the trials of Molitor et al. [6] in VSP, significant effects were mainly observed when comparing early (pre-flowering or flowering) and very late (2 to 4 weeks after end of flowering) first shoot toppings. 
However, (first) carrying out shoot topping in SMPH more than one week after the end of flowering might not be practically feasible (at least where the distance between rows is around $2.0 \mathrm{~m}$ and the plant vigor on a moderate level). Indeed, further unlimited shoot growth and, in consequence, the closure of the driving lane between rows might hinder proper plant protection treatments by tractor-driven sprayers in this period of highest susceptibility of young berries towards downy and powdery mildew, as well as black rot.

\subsection{Mechanical Thinning}

Mechanical thinning using a harvest machine reduced yield by between 28\% (moderate thinning) and 53\% (severe thinning) on average between 2014 and 2018, compared to the non-thinned SMPH treatments. Yield reduction is based on a lower berry number as well as on reduced berry size [4], both of which lead to looser cluster structures as confirmed by the tendencies in the present data. Consequently, both thinning regimes further delayed the day of the year for reaching $5 \%$ disease severity as well as the inclination of the disease progress curves. However, in some cases, an earlier start of the bunch rot epidemic was observed in the thinned treatments of SMPH. This is the result of unripe berries being damaged by the harvest machine followed by humid weather conditions in the subsequent period. Here, damaged berries were most likely infected by Botrytis cinerea, while, where dry weather conditions followed, damaged berries dried out completely.

Analyses of the maturity progress indicate that at early dates of maturity control, the increase of TSS caused by yield reduction due to mechanical thinning is often low or even absent compared to non-thinned treatments of SMPH, while, close to harvest, TSS levels were often comparable with the standard treatment, VSP. We assume that mechanical thinning causes a shock for the grape berries and stops ripening for several days, comparable to a ripening stop as the result of hail damage in this stage. After this period of ripening disruption, induced by the reduced remaining crop load, the further maturity progress in the thinned treatments continued at a faster pace than in the non-thinned treatments. Due to a combination of both (i) the delay of the bunch rot epidemic and (ii) the acceleration of the maturity progress of grape maturity, the level of TSS at the moment of reaching $5 \%$ disease severity in the thinned treatments is higher than in the non-thinned SMPH treatments or in VSP.

\subsection{Practical Recommendations}

The present study has revealed the limitations, challenges, and opportunities of the relatively novel viticultural training system SMPH in practical conditions.

Based on the present results, the impact of the timing of shoot topping appears to be limited and might be neglected in practical viticulture.

The present study, as well as that of Walg et al. [4] revealed that, especially in the year of transfer from VSP to SMPH, the yield might be too high for premium quality wine production. For example, in the year of transfer, the minimum threshold of TSS for wine of protected designation of origin was not reached in the non-thinned treatments of SMPH due to the very high crop load. This is probably the result of the two-year yield formation process $[14,21]$, where the number of clusters per shoot is already determined in the year prior to harvest (i.e., in our case, the final year before transfer from the VSP system). Consequently, especially in years with a high yield potential (e.g., the first year after transfer from VSP), it is recommended to mechanically thin the yield to a moderate level to safeguard proper wine quality [4]. In the present trials, the percentage of yield reduction was on average $28 \%$ (moderate thinning) or $53 \%$ (severe thinning). However, the level of reduction was not stable over time and ranged between -1 (2016) and 64\% (2018) for moderate thinning and between 15 (2016) and 84\% (2018) for severe thinning even though the same machine and identical beat frequency were used. Observed differences in the degree of yield reduction might be caused by small differences in the phenological development (even though thinning took always place in $\mathrm{BBCH}$ 79) or in the annual crop load. Especially in years with high crop levels, the berry development is usually relatively inhomogeneous. Berry resistance to detachment is linked to the development of the 
berries. Consequently, inhomogeneous development might lead to a higher uncertainty in the degree of yield reduction caused by mechanical thinning.

In 2016, which had a generally low crop level in all SMPH treatments, the percentage of yield reduction was low in both thinning treatments. Generally, the observed fluctuation in the percentage of yield reduction indicates the challenge of exact determination of the degree of mechanical thinning. While in some years the yield reduction might be too low to avoid over-cropping, in other years the reduction might lead to economically non-profitable low yields. Consequently, further investigations are necessary to provide a more precise adjustment of the degree of yield reduction.

High disease severities were observed at early assessment dates in the thinned treatments of SMPH, especially in 2016, where the mechanical thinning took place close to veraison. Between fruit set and veraison, young, immature grape berries are highly resistant to B. cinerea [22], while, after veraison, the host defence progressively breaks down with ongoing maturation [23]. At the time of mechanical thinning in 2016, single berries might had already gone soft and were hence more susceptible towards B. cinerea than unripe, hard berries. Based on this effect observed in 2016, it might be speculated that mechanical thinning should not take place too late in the season, i.e., clearly prior to veraison.

\subsection{SMPH as a Climate Change Adaptation Strategy}

Generally, a ripening delay was observed in SMPH compared to VSP. This ripening delay represents a risk for full grape maturity in the case of late maturation, such as in late vintages and/or late-ripening cultivars and/or late-ripening vineyards or regions. Consequently, SMPH systems should be avoided where heat consumption usually represents a limiting factor for full maturity (non-thinned).

On the other hand, the observed delay of the maturity progress might potentially turn into a benefit in future climatic conditions. Climate change projections are afflicted by uncertainties caused by mainly three factors: natural variability, model uncertainty, and greenhouse gas (GHG) emission scenario uncertainty [24]. Even though uncertainties in climate change projections exist depending on the underlying greenhouse gas emission scenarios, an annual air temperature increase of approximately $2.6^{\circ} \mathrm{C}$ is projected for the region of investigation in the far future (2061-2090) compared to the reference period 1971-2000 [19].

The observed delayed maturation in SMPH and the shift of the maturation period towards later, usually cooler parts of the year, as well as the prolongation of the maturation period (due to cooler temperatures), might contribute to conserving the freshness and lightness [25] that is especially exemplary for white wines in (by then formerly) cool climate grapegrowing regions, such as Luxembourg. Here, SMPH could represent an interesting climate change adaptation strategy.

Additionally, extreme weather events causing, e.g., hail or sunburn damage are likely to occur more frequently if climate conditions change [26]. Here, SMPH might represent an adequate low-yield risk minimization strategy. Damage caused by hail, frost, or sunburn was usually found to be lower in SMPH [4] than in VSP due to (i) the higher yield potential and (ii) the specific distribution of clusters in the canopy. While in the past, the labor and cost benefits were the main drivers of the spread of SMPH vineyards, with ongoing climate change, the morphological and physiological characteristics of SMPH [4] are likely to gain increasing importance.

The lower susceptibility towards bunch rot observed might additionally be an opportunity for the SMPH system, especially in vineyards and/or cultivars where the emerging bunch rot epidemic represents the limiting factor for full grape maturity on a routine basis. This will especially be the case in expected future climatic conditions, since temperature has been observed as the major driver of the bunch rot epidemic [17], suggesting the occurrence of more severe bunch rot epidemics in future climatic conditions.

On the one hand, the lower susceptibility of SMPH towards bunch rot might allow for a pesticide reduction in viticulture. On the other hand, the investigations of Kraus et al. [1] indicated a higher susceptibility of SMPH to downy and powdery mildew, as well as to Drosophila suzukii due to 
the micro-climatic conditions inside the extended canopy. To the best of our knowledge, the net effect concerning pesticide consumption in SMPH has not yet been quantified and thus merits further investigations.

\section{Conclusions}

Due to the (i) delay of the bunch rot epidemic, (ii) the delay maturity period towards later, usually cooler, times of the year, and (iii) the lower risk of inadequate yields caused by extreme weather events (such as late frost, hail, or sunburn damage), SMPH might compensate for some of the potentially negative effects of climate change and might hence represent an interesting climate change adaptation strategy for practical viticulture in (formerly) cool climate viticulture regions.

Supplementary Materials: The following are available online at http:/ /www.mdpi.com/2073-4395/9/4/173/s1, Table S1: Dates of shoot topping and corresponding exact phenological stages (BBCH code according to Lorenz et al. (1995)) in different treatments between 2013 and 2018, Table S2: Key growing season (April-October) and annual meteorological data of Remich/Luxembourg between 2013 and 2018, Table S3: Average values of the percentage of bud burst 2014-2018 (no assessment in 2013), as well as average normalized percentage of bud burst values for 2014-2018 (value of the percentage of bud burst of the respective treatment in a specific year/value of the standard treatment, VSP, in this year), Table S4: Average values of the number of inflorescences per shoot 2014-2018 (no assessment in 2013), as well as average normalized number of inflorescences per shoot values for 2014-2018 (value of the number of inflorescences per shoot of the respective treatment in a specific year/value of the standard treatment, VSP, in this year), Table S5: Average values of the density index between 2013 and 2018 as well as average normalized density index values for 2014-2018 (value of the density index of the respective treatment in a specific year/value of the standard treatment, VSP, in this year), Table S6: B. cinerea disease severities in the different treatments at the different assessment dates between 2013 and 2018. Treatments in the same year at the same assessment date marked with the same letter did not differ significantly (according to Tukey's multiple comparison procedure $(p \leq 0.05))$, Table S7: Parameters describing the Botrytis cinerea disease progress plotted against the time according to the sigmoidal equation type $y=100 /\left(1+e^{-\left(\left(x-x_{0}\right) / b\right)}\right)$, Table S8: Total soluble solids in the different treatments at the different assessment dates between 2013 and 2018. Treatments in the same year at the same assessment date marked with the same letter did not differ significantly (according to Tukey's multiple comparison procedure $(p \leq 0.05))$, Table S9: Parameters describing the maturation progress plotted against the time according to the sigmoidal equation type $y=a /\left(1+e^{-\left(\left(x-x_{0}\right) / b\right)}\right)$, Table S10: Parameters describing the disease progress plotted against the maturation progress according to the sigmoidal equation type $y=100 /\left(1+e^{-\left(\left(x-x_{0}\right) / b\right)}\right)$.

Author Contributions: All authors have made substantial contributions to the present work. The authors agree to be personally accountable for the author's own contributions and for ensuring that questions related to the accuracy or integrity of any part of the work, even ones in which the author was not personally involved, are appropriately investigated, resolved, and documented in the literature. Individual contributions: Conceptualization: D.M., R.M.; Methodology: D.M., M.B.; Investigation: D.M., M.P.-B., M.S., R.M.; Writing-Original Draft Preparation: D.M., M.P.-B., M.B.; Writing—Review \& Editing: M.S., R.M., L.H.

Funding: This work was partly funded by the IVV (Remich/Luxembourg) in the framework of the "ProVino", "BioViM", and "TerroirFuture" research projects, as well as by the European Union in the framework of the "Clim4Vitis" research project (Horizon 2020 research and innovation programme; grant agreement No. 810176).

Acknowledgments: The authors would like to thank R. Rausch, L. Vesque, B. Biewers, J. Niewind, B. Untereiner, D. Dam, M. Behr (LIST-Luxembourg Institute of Science and Technology), S. Garidel, S. Cerqueira, C. Beissel, P. Zahlen, L. Gilbertz, J. Lafleur, H. Litjens, J. Koch, C. Blum, and S. Fischer (Institut Viti-vinicole, IVV) for their technical support in the experimental vineyard and in the laboratory, J. Junk (LIST) for fruitful discussions, the Weinbau-Lohnunternehmen Meierer for mechanical thinning, as well as L. Auguin (LIST) for proofreading and language-editing.

Conflicts of Interest: The authors declare no conflict of interest.

\section{References}

1. Kraus, C.; Pennington, T.; Herzog, K.; Hecht, A.; Fischer, M.; Voegele, R.T.; Hoffmann, C.; Töpfer, R.; Kicherer, A. Effects of canopy architecture and microclimate on grapevine health in two training systems. Vitis 2018, 57, 53-60.

2. Clingeleffer, P.R. Development of management systems for low cost, high quality wine production and vigour control in cool climate Australian vineyards. Wein-Wissenschaft 1993, 48, 130-134. 
3. Intrieri, C.; Filippetti, I.; Allegro, G.; Valentini, G.; Pastore, C.; Colucci, E. The semi-minimal-pruned hedge: A novel mechanized grapevine training system. Am. J. Enol. Viticult. 2011, 62, 312-318. [CrossRef]

4. Walg, O.; Blätz, M.; Friedel, M. Minimalschnitt im Spalier-eine wirksame Möglichkeit zur Spätfrostprävention. In Deutsches Weinbau-Jahrbuch 2019; Schultz, H.R., Stoll, M., Eds.; Eugen Ulmer KG: Stuttgart, Germany, 2018; Volume 70, pp. 76-85.

5. Petrie, P.R.; Clingeleffer, P. Crop thinning (hand versus mechanical), grape maturity and anthocyanin concentration: Outcomes from irrigated Cabernet Sauvignon (Vitis vinifera L.) in a warm climate. Aust. J. Grape Wine Res. 2008, 12, 21-29. [CrossRef]

6. Molitor, D.; Baron, N.; Sauerwein, T.; André, C.M.; Kicherer, A.; Döring, J.; Stoll, M.; Beyer, M.; Hoffmann, L.; Evers, D. Postponing first shoot topping reduces grape cluster compactness and delays bunch rot epidemic. Am. J. Enol. Viticult. 2015, 66, 164-176. [CrossRef]

7. Lorenz, D.H.; Eichhorn, K.W.; Bleiholder, H.; Klose, R.; Meier, U.; Weber, E. Phenological growth stages of the grapevine, Vitis vinifera L. ssp. vinifera. Codes and descriptions according to the extended BBCH scale. Aust. J. Grape Wine Res. 1995, 1, 100-103. [CrossRef]

8. Ipach, R.; Huber, B.; Hofmann, H.; Baus, O. Richtlinie zur Prüfung von Wachstumsregulatoren zur Auflockerung der Traubenstruktur und zur Vermeidung von Fäulnis an Trauben. Outline for an EPPO-Guideline; DLR Rheinpfalz: Neustadt an der Weinstraße, Germany, 2005.

9. Evers, D.; Molitor, D.; Rothmeier, M.; Behr, M.; Fischer, S.; Hoffmann, L. Efficiency of different strategies for the control of grey mold on grapes including gibberellic acid (Gibb3), leaf removal and/or botryticide treatments. J. Int. Sci. Vigne Vin 2010, 44, 151-159. [CrossRef]

10. Molitor, D.; Hoffmann, L.; Beyer, M. Flower debris removal delays grape bunch rot epidemic. Am. J. Enol. Viticult. 2015, 66, 548-553. [CrossRef]

11. Beresford, R.M.; Evans, K.J.; Wood, P.N.; Mundy, D.C. Disease assessment and epidemic monitoring methodology for bunch rot (Botrytis cinerea) in grapevines. N. Z. Plant Prot. 2006, 59, 1-6.

12. Coombe, B.G. Research on development and ripening of the grape berry. Am. J. Enol. Viticult. 1992, 43, 101-110.

13. Molitor, D.; Biewers, B.; Junglen, M.; Schultz, M.; Clementi, P.; Permesang, G.; Regnery, D.; Porten, M.; Herzog, K.; Hoffmann, L.; et al. Multi-annual comparisons demonstrate differences in the bunch rot susceptibility of nine Vitis vinifera L. cv. Riesling clones. Vitis 2018, 57, 17-25.

14. Keller, M. The Science of Grapevines. Anatomy and Physiology, 2nd ed.; Elsevier Academic Press: London, UK, 2015.

15. Tello, J.; Ibanez, J. What do we know about grapevine bunch compactness? A state-of-the-art review. Aust. J. Grape Wine Res. 2017, 24, 6-23. [CrossRef]

16. Hed, B.; Ngugi, H.K.; Travis, J.W. Relationship between cluster compactness and bunch rot in Vignoles grapes. Plant Dis. 2009, 93, 1195-1201. [CrossRef] [PubMed]

17. Molitor, D.; Baus, O.; Hoffmann, L.; Beyer, M. Meteorological conditions determine the thermal-temporal position of the annual Botrytis bunch rot epidemic on Vitis vinifera L. cv. Riesling grapes. Oeno One 2016, 50, 231-244. [CrossRef]

18. Molitor, D.; Behr, M.; Hoffmann, L.; Evers, D. Impact of grape cluster division on cluster morphology and bunch rot epidemic. Am. J. Enol. Viticult. 2012, 63, 508-514. [CrossRef]

19. Molitor, D.; Junk, J. Climate change is implicating a two-fold impact on air temperature increase in the ripening period under Central European climate conditions. Oeno One 2019. submitted.

20. Junk, J.; Görgen, K.; Rapisarda, C.; Eickermann, M. Climate change and agriculture: Impact assessment for Luxembourg based on multi-model EURO-CORDEX simulations. Annalen der Meteorologie 2017, 52, 49.

21. Molitor, D.; Keller, M. Yield of Müller-Thurgau and Riesling grapevines is altered by meteorological conditions in the current and the previous growing seasons. Oeno One 2016, 50, 245-258.

22. Hill, G.; Stellwaag-Kittler, F.; Huth, G.; Schloesser, E. Resistance of grapes in different developmental stages to Botrytis cinerea. Phytopathologische Zeitschrift 1981, 102, 328-338. [CrossRef]

23. Kretschmer, M.; Kassemeyer, H.H.; Hahn, M. Age-dependent grey mould susceptibility and tissue-specific defence gene activation of grapevine berry skins after infection by Botrytis cinerea. J. Phytopathol. 2007, 155, 258-263. [CrossRef]

24. Latif, M. Uncertainty in climate change projections. J. Geochem. Explor. 2011, 110, 1-7. [CrossRef] 
25. Jackson, D.I.; Lombard, P.B. Environmental and management practices affecting grape composition and wine quality-A review. Am. J. Enol. Viticult. 1993, 44, 409-430.

26. IPCC. Managing the risks of extreme events and disasters to advance climate change adaptation. In A Special Report of Working Groups I and II of the Intergovernmental Panel on Climate Change; Field, C.B., Barros, V., Stocker, T.F., Qin, D., Dokken, D.J., Ebi, K.I., Mastrandrea, M.D., Mach, K.J., Plattner, G.-K., Allen, S.K., et al., Eds.; Cambridge University Press: Cambrige, UK; New York, NY, USA, 2012; p. 582. 